\title{
Recurrent skin ulcer cross-repair and sensory reconstruction in a WRN gene mutational patient ${ }^{*}$
}

\author{
Jiqiang $\mathrm{He}^{1}$ \\ Panfeng $\mathrm{Wu}^{1}$
}

\author{
Ding $\operatorname{Pan}^{1}$ \\ Juyu Tang ${ }^{1}$
}

DOI: http:/ / dx.doi.org/10.1590/abd1806-4841.20187517

\begin{abstract}
A 37-year-old man complained of a refractory posterior malleolar ulceration on his left ankle. He was diagnosed with Werner syndrome according to the progeroid clinical features and genetic testing. To approach the ulceration, a free flow-through right anterolateral thigh perforator flap with anterolateral thigh cutaneous nerve was harvested. One year later, he was readmitted due to a new ulceration on his right ankle. We harvested the left anterolateral thigh perforator flap with anterolateral thigh cutaneous nerve to reconstruct the defect. After one more year of follow-up, there was no recurrence of ulcers, and the sensation of the flap recovered partially after 6 months. We conclude that free flow-through anterolateral thigh perforator flap is a feasible choice for the repair of foot ulcers in Werner syndrome.
\end{abstract}

Keywords: Perforator flap; Reconstructive surgical procedures; Skin ulcer; Werner syndrome

\section{INTRODUCTION}

Werner's syndrome is a rare, autosomal recessive condition with multiple progeroid features. It was first described by Otto Werner in $1904 .{ }^{1}$ It is characterized by bilateral cataracts, premature graying, dermatologic changes and short stature, intractable skin ulcers, bird-like facies, and abnormal voice. ${ }^{2}$ Confirmation of a clinical diagnosis requires $W R N$ gene testing. ${ }^{3}$

Although it is difficult to repair the cutaneous ulcers in Werner's syndrome, their prevention or reduction of recurrence is extremely important. First, a definite diagnosis should be made. Incorrect diagnosis and inappropriate therapeutic regimen may increase the risk of amputations because of incurable ulceration. We report a typical case treated with contralateral innervated free flowthrough anterolateral thigh (ALT) perforator flaps to repair ulcers on both heels. To our knowledge, this is the first report of this technique for the treatment of refractory ulcers in Werner syndrome.

\section{CASE REPORT}

A 37-year-old man was admitted for evaluation and treatment of skin ulcers on his left lower limb. The patient had depressed scars, epidermis fibrosis, and hyperpigmentation on both lower ex- tremities. There was a family history of consanguineous marriage. The patient had no history of trauma or deep vein thrombosis. Physical examination revealed short stature $(142 \mathrm{~cm})$ and body weight $37 \mathrm{~kg}$. The patient had slender extremities, prematurely gray hair, atrophy of the skin and subcutaneous tissue, beak-shaped nose, high-pitched voice, and juvenile cataracts. X-ray revealed calcification of the Achilles tendon. Doppler ultrasound showed moderate arteriosclerosis in both lower extremities. Genetic analysis revealed a homozygous mutation, a $\mathrm{T}$ to $\mathrm{C}$ substitution at the splice site of intron 28 of WRN gene (IVS28+2C, Figure 1).

Previous local pedicle flap had been transferred to repair the ulcer, but the ulcer reccured and the Achilles tendon was exposed (Figure 2A). Because of the previous injury to local vessels and the poor blood supply to the distal foot due to arteriosclerosis, the decision was made to harvest a contralateral flow-through ALT perforator flap with anterolateral thigh cutaneous nerve (Figure 2B). After surgical debridement, we measured the size of the defect and dissected an ALT perforator flap on the right donor site. The flap was then transferred to the recipient site (Figure 2C). The proximal descending branch of lateral circumflex femoral artery was anasto-

Received 11 August 2017.

Accepted 05 September 2017.

* Work conducted at the Xiangya Hospital of Central South University, Xiangya Road, Changsha, China.

Financial support: National Natural Science Foundation of China (81472104).

Conflict of interest: None.

1 Department of Hand and Microsurgery, Xiangya Hospital of Central South University, Xiangya Road, Changsha, China.

MAILING AdDRESS:

Juyu Tang

E-mail: tangjuyu@csu.edu.cn

C2018 by Anais Brasileiros de Dermatologia 
mosed to the proximal posterior tibial artery, and the distal branch was anastomosed to the distal posterior tibial artery. The two veins of the flap were respectively anastomosed to two veins accompanied with the posterior tibial artery. Finally, the anterolateral femoral cutaneous nerve was coaptated to the recipient medial calcaneal nerve. The flap survived and recovered protective sensation at 12 months' follow-up (Figure 2D).

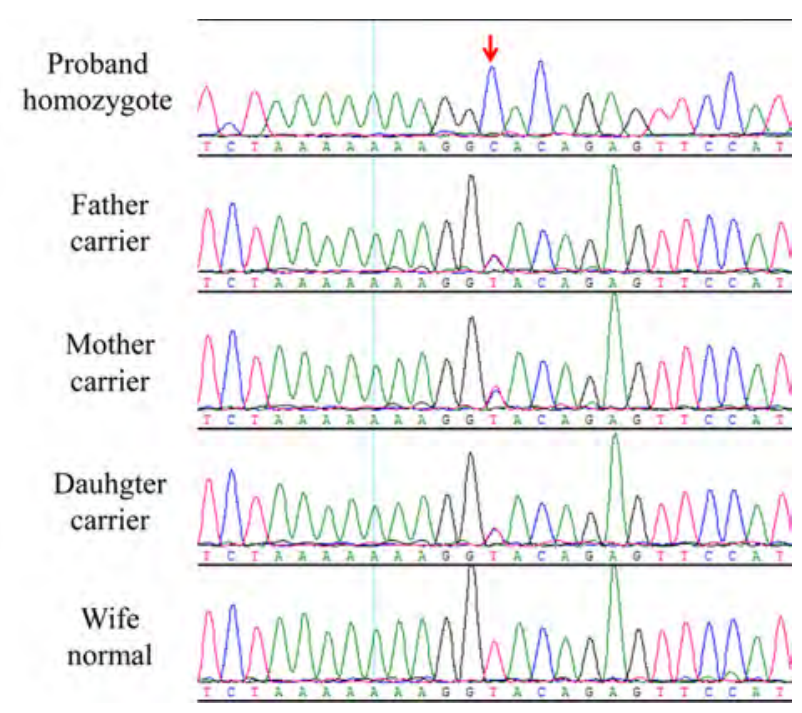

Figure 1: WRN gene analysis. A T to $C$ substitution at the splice site of intron 28 of WRN gene (IVS28+2C)
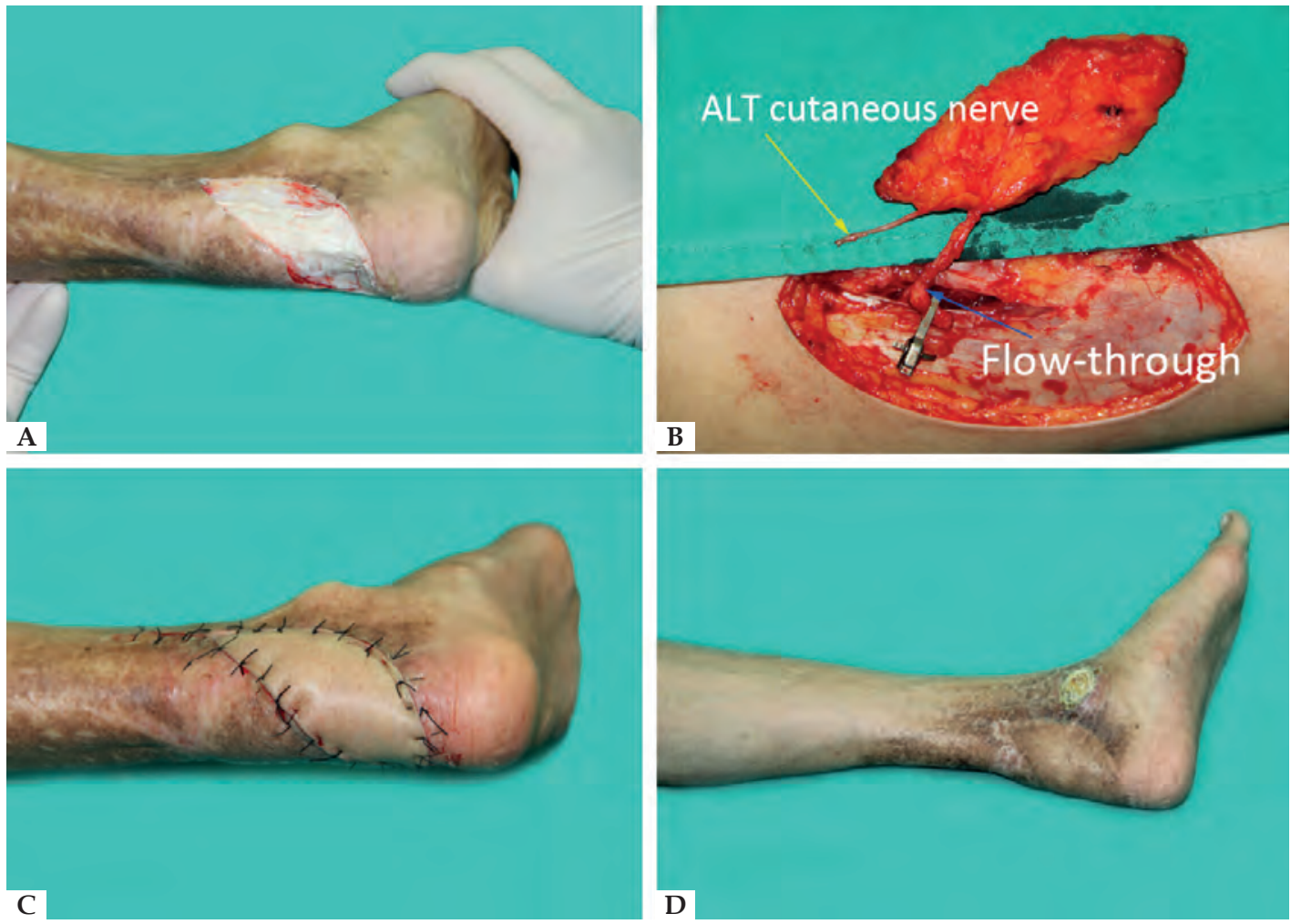

Figure 2: A - Ulcer and calcification of the Achilles tendon on the left heel; B - Free flow-through ALT flap $(11 \times 4 \mathrm{~cm})$ with anterolateral thigh cutaneous nerve was designed and harvested; C - Left heel: The flap was transferred to the recipient site; D - Left heel: 12 month-follow up
However, the patient complained of a right posterior malleolar ulceration after one year and was readmitted (Figure 3A). After adequate debridement, a contralateral free flow-through ALT perforator flap was designed to cover the defect (Figure 3B). Vascular anastomosis method was similar as before. The postoperative care was uneventful. So far there has been no further development of ulcer on either heel, only inconspicuous linear scars in the donor site (Figure 3C and 3D).

\section{DISCUSSION}

Werner's syndrome is usually accompanied by metabolic abnormalities in the connective tissue, arteriosclerosis, diabetes, ectopic calcification, and atrophy of the subcutaneous tissue and muscle. ${ }^{4}$ Ulcer in the extremity is one of the most difficult clinical problems in patients with Werner's syndrome. ${ }^{5}$ Thus, seeking an effective method to repair this specific ulceration is highly significant.

Numerous studies have reported different methods to repair ulcers (Chart 1) ${ }^{6-10}$ First, skin grafting is not recommended. Due to the poor blood supply to the ulcer base, a skin graft does not easily survive. Even if the grafted skin survives, the ulcer is hardly resistant and easily relapses. Second, local pedicle flaps are not useful for the treatment of intractable ulcers of the extremities because of scleroderma-like skin lesions and poor blood supply. Our patient had failed to heal the wound with a local pedicle flap. It is thus advisable to carefully assess the patient's general clinical status before surgery if one chooses a pedicle flap. Third, muscle or musculocuta- 
neous flaps, including flexor carpi ulnar muscle flap and latissimus dorsi flap, should be used with caution in the Werner's syndrome patient because of the functional loss at the donor site. Moreover, the musculocutaneous flap is bulky and unable to carry the nerve to reconstruct sensation.
We thus use contralateral free flow-through ALT perforator flaps with anterolateral femoral cutaneous nerves for the repair of heel ulcer in Werner syndrome. There are numerous advantages: (1) Flow-through technique enables the vascular pedicle to maintain dual blood supply of flap and distal extremity. (2) In Werner syndrome, it
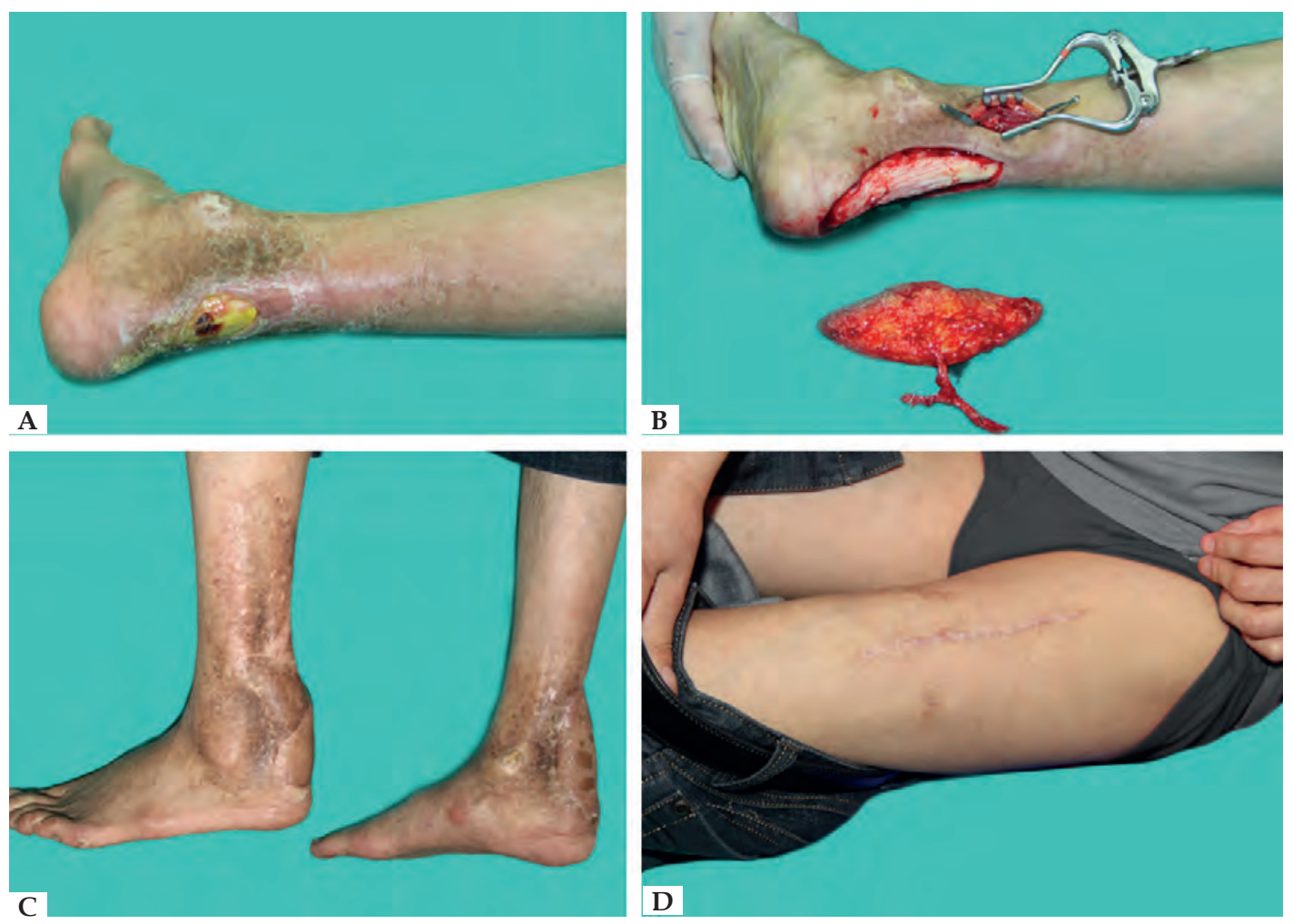

FigURE 3: A - Right heel ulcer: 1 year after the first operation; B - Free flow-through ALT flap $(13 \times 5 \mathrm{~cm})$ was transferred to the recipient area; C - Bilateral heel: 15 month follow -up; D - Linear scars in the donor site

\begin{tabular}{|c|c|c|c|c|c|c|}
\hline & $\begin{array}{l}\mathrm{N}^{\circ} \text {. of } \\
\text { cases }\end{array}$ & Ulcer Position & Reconstructive method & Dorner site & complication & Recurrence \\
\hline $\begin{array}{l}\text { Koshima, et al } \\
\text { (1989) }\end{array}$ & 2 & Right elbow & $\begin{array}{l}\text { Case1: Flexor carpi ulnar } \\
\text { muscle flap and skin graft } \\
\text { Case2: inferior ulnar recur- } \\
\text { rent artery perforator flap }\end{array}$ & $\begin{array}{l}\text { Case 1: closed primarily } \\
\text { Case 2: skin graft }\end{array}$ & No & No \\
\hline $\begin{array}{l}\text { Salinas, et } a l^{5} \\
\text { (1995) }\end{array}$ & 1 & Right elbow & Island lateral arm flap & Closed primarily & No & No \\
\hline $\begin{array}{l}\text { Okazaki, et al } \\
\text { (1998) }\end{array}$ & 1 & Right heel & Lateral Supramalleolar Flap & Skin graft & $\begin{array}{l}\text { Partial der- } \\
\text { mal necrosis }\end{array}$ & No \\
\hline $\begin{array}{l}\text { Taniguchi, et } \text { al }^{7} \\
\text { (1998) }\end{array}$ & 1 & Right knee & $\begin{array}{l}\text { Right latissimus Doris mus- } \\
\text { culocutaneous flap }\end{array}$ & Closed primarily & No & No \\
\hline $\begin{array}{l}\text { Yeong, et al } \\
\text { (2004) }\end{array}$ & 2 & $\begin{array}{l}\text { Case1: Right } \\
\text { ankle, lateral } \\
\text { border and the } \\
\text { heel of the right } \\
\text { foot } \\
\text { Case 2: Fourth } \\
\text { and fifth toes, } \\
\text { the heel and } \\
\text { the ankle }\end{array}$ & Skin graft & NA & NA & NA \\
\hline
\end{tabular}

$\mathrm{NA}=$ not available or unknown from literature. 
is suitable to repair limb ulcers with ALT flaps owing to lipoatrophy of the thigh. Our patient's fat thickness was $8 \mathrm{~mm}$, and the recipient site developed a satisfactory appearance. (3) Patients with Werner's syndrome have arteriosclerosis, so sacrificing major vessels should be avoided if possible, because it can cause irreversible damage to circulation in the lower leg in the future. A flow-through ALT perforator flap with the lateral femoral cutaneous nerve not only handily bridges the posterior tibial artery but also acquires partial sensation.
(4) With protective sensation, the patient can wear shoes and walk normally. (5) The donor site was closed primarily in this case, and only linear scars were left at the donor site.

We conclude that contralateral free flow-through ALT perforator flap is a feasible choice for repair of heel defects in patients with Werner syndrome. The anterolateral thigh cutaneous nerve can be transferred with the flap to recover protective sensation.

\section{REFERENCES}

1. Werner 0. Uber Katarakt in Verbindung mit Sklerodermie [dissertation]. Kiel: Kiel University; 1904.

2. Mansur AT, Elçioglu NH, Demirci GT. Werner syndrome: clinical evaluation of two cases and a novel mutation. Genet Couns. 2014;25:119-27.

3. Oshima J, Sidorova JM, Monnat RJ Jr. Werner syndrome: Clinical features, pathogenesis and potential therapeutic interventions. Ageing Res Rev. 2017;33:105-114.

4. Fumo G, Pau M, Patta F, Aste N, Atzori L. Leg ulcer in Werner syndrome (adult progeria): a case report. Dermatol Online J. 2013;19:6.

5. Yamamoto K, Imakiire A, Miyagawa N, Kasahara T. A report of two cases of Werner's syndrome and review of the literature. J Orthop Surg (Hong Kong). 2003:11:224-33

$\begin{array}{ll}\text { Jiqiang He } & \text { (iD) ORCID 0000-0001-9827-6897 } \\ \text { Ding Pan } & \text { (D) ORCID 0000-0003-3537-4750 }\end{array}$

6. Koshima I, Shozima M, Soeda S. Repair of elbow defects and the biochemical characteristics of Werner's syndrome. Ann Plast Surg. 1989;23:357-62.

7. Salinas Velasco VM, Herrero Fernandez F, García-Morato V, Alonso Martínez S. Coverage of elbow ulcers in a patient with Werner's syndrome. Ann Plast Surg. 1995;35:423-8.

8. Okazaki M, Ueda K, Kuriki K. Lateral supramalleolar flap for heel coverage in a patient with Werner's syndrome. Ann Plast Surg. 1998;41:307-10.

9. Taniguchi $Y$, Tamaki T. Reconstruction of intractable ulcer of the knee joint in Werner's syndrome with free latissimus dorsi myocutaneous flap. J Reconstr Microsurg. 1998;14:555-8.

10. Yeong EK, Yang CC.Chronic leg ulcers in Werner's syndrome. Br J Plast Surg. 2004:57:86-8

How to cite this article: He J, Pan D, Wu P, Tang J. Recurrent skin ulcers cross-repair and sensory reconstruction in a WRN gene mutational patient. An Bras Dermatol. 2018;93(3):443-6. 